\title{
The Need to Unmask Lurking False Friends: Sustainability Is a State, Not a Process! - a Reply to Fernandez et al. (2012)
}

\author{
Adrian Monjeau ${ }^{1,2 *}$, Jo Anne Smith-Flueck ${ }^{3} \&$ Werner Flueck ${ }^{2,3}$
}

\author{
${ }^{1}$ Programa de Ecofilosofía, Departamento de Filosofía, Fundación Bariloche, Argentina \\ ${ }^{2}$ Consejo Nacional de Investigaciones Científicas y Técnicas, Argentina \\ ${ }^{3}$ Instituto de Análisis de Recursos Naturales, Universidad Atlántida Argentina, Argentina
}

\begin{abstract}
Monjeau (2010, p. 117) concluded that "a possible way out from conservation crossroads might consist in being able to distinguish friends from dangerous enemies" and that conservation in Latin America is "full of Trojan horses". This was in reference to the quantity of deceits hidden behind certain concepts, which although offered as promising solutions for conservation are also highly ambiguous. One such concept is "sustainable development".
\end{abstract}

We applaud Fernandez et al. (2012) for their valuable article in the recent issue of Natureza \& Conservação, pointing out that about half of the endeavors of natural resource extraction labeled as "sustainable", in Brazil, are actually unsustainable. The article perfectly exemplifies the metaphors of Trojan horses and false friends. False friends are worse than recognized enemies, because the latter are more predictable. Relying on false friends is like placing our love and respect for Nature into the hands of Mata Hari. Analyses like that done by Fernandez et al. are urgent and indispensable to determine who is who. It would be interesting to continue to investigate this problem intending to discover patterns of success and failure regarding sustainable resource use: are outcomes according to chance? Or perhaps success or failure occurs according to some characteristic pattern? Once such knowledge exists, financial support and the label "sustainable" should only be channeled to the reliable hands of those who aim at effective biodiversity conservation via sustainable programs according to the Bruntland concept.

With regards to terrestrial natural resource extraction, sustainability refers, among others, to keeping exploited populations below carrying capacity, as productivity is maximized at intermediate densities (Fernandez et al. 2012). Hence, under such exploitation, biomass export rates are optimized, thereby greatly altering dynamics of nutrient flux. Not only is the loose usage of "sustainable"

\footnotetext{
*Send correspondence to: Adrian Monjeau

Programa de Ecofilosofía, Departamento de Filosofía,

Fundación Bariloche, Km 9.5, Bariloche, Argentina

E-mail: amonjeau@gmail.com
}

dangerous, but also for the natural world it is crucial to correctly address irreversible hierarchical relationships dictated by biophysical laws. Viewed from an ecosystem perspective, there does not exist any 'social' nor 'economic' sustainability (De Angelis 1992). For instance, it is futile to protest against food shortage or high pricing when the underlying biophysical limit is dependent on the import of phosphorous. We agree with Fernandez et al. on the importance of demography to monitor processes determining sustainability. In the short-term demography serves as an indisputable indicator and is easy to measure. However, we believe that we should expand criteria used for a diagnosis by considering higher hierarchical levels of ecosystem processes. We would like to contribute to the article by Fernandez et al. by expanding the list of false friends to include misleading for instance categorization of protected areas. Besides, we would like to suggest other indicators of sustainability that should be measured, particularly regarding biophysical limits (e.g. mass balance in biogeochemical cycles). The scope of conservation categories for protected areas of IUCN (e.g. I to VI) or other categorizations like World Natural Heritage (UNESCO) should share a minimal foundation for conservation objectives. In protected areas where natural resources are managed, the use of these resources is supposedly sustainable. In such areas, the management requires the co-participation and/or consensus of local people, which constitutes the priority of political vision. Although this approach might be politically correct (Peterson et al. 2005), it is difficult to imagine how to get to a logical derivation of steps that are conducive to ecologically correct decisions in the long term (Monjeau 2010).

A consensus reached by relying on popular opinions may result in adopting various anthropocentric interests regarding the fate of a protected area, yet differ from decisions aiming to prevent extinctions and maintain ecosystem viability. Governments can be successful, or not, in achieving explicit conservation objectives. Cases declared to present supposed conservation successes are 
frequently based on false surrogates of biodiversity like canopy cover via satellite images when such cover could mask the impact from hunting (Redford 1992) or livestock, with their effects on nutrient cycles (Flueck et al. 2011).

Biogeochemical nutrient cycles are rarely considered when referring to the export of biomass of vegetation (forest products, burning) and animals (via hunting and livestock) (Flueck \& Smith-Flueck 2006; Flueck 2010). Biomass export via livestock, hunting and forest products results in the loss of essential nutrients like phosphorous, selenium or iodine, because the naturally local recycling is changed to continuous nutrient loss, without concurrent replacement. Such chemical elements are essential for proper ecosystem functioning, and their export from anthropogenic activities results in a gradual deterioration of ecosystem capacity to retain its processes and biodiversity (DeAngelis 1992; Flueck et al. 2012). Thus, demographic analyses showed that forest harvesting based on 30 year rotations as defined by Brazilian law for Amazonia were too short (Fernandez et al. 2012), yet the additional consideration of skewed nutrient concentrations principally in biomass in such areas would indicate much larger effects from biophysical limits. Elsewhere, at harvest intervals of 35 years, up to $62 \%$ of the total nutrient pool was removed (Dyck \& Cole 1994).

While effects from nutrient limitations at the individual level might be trivial, they can have strong effects at the population level, including local extinctions. As generally accepted, environmental impact studies are at the core of sustainability concerns, but they need to include life-cycle analysis of important nutrients. To a lesser extent, strictly protected areas can also be subject to these problems, because many suffer impacts originating from surrounding areas, and sometimes represent the last sources for natural resources in regions with high anthropic demands. When conservation objectives are not achieved, a commonly espoused excuse is that required solutions are utopic (which means "politically hard to implement") as if this was reason to consider the problem resolved as good as is possible. This is an unacceptable laissez-faire attitude. However, such areas with failed conservation implementation continue to benefit from being categorized as a protected area where conservation is supposedly practiced. Not only is the true geographic extent of such a protected area smaller than presented, but implicitly its category shows, misleadingly, an area being under appropriate management, i.e. the area is supposedly protected for conservation goals, and therefore, without need for additional intervention.

In our opinion, such situations need to be unmasked and the areas re-categorized in order to represent more realistically their conservation status. Beyond sole demographics of focal species, protected areas should preserve natural ecological processes, which for several important nutrients are practically steady state cycles under natural conditions. Where malpractice by officials is involved, they should be held responsible for mismanagement of public domains.
One way to improve the utility of the banners of IUCN or UNESCO is to use them as a tool to create international pressure on high-level environmental government agencies. We imagine, perhaps naively, that no country president would like to have a World Natural Heritage site removed from the UNESCO list, for being recognized as incapable of sustaining international compromises, or for having his/ her name associated with the fall of a national park. For example, in 2007, the Arabian Oryx Sanctuary in Oman became the first "ex-World Heritage site": the delisting removed funding support, and the situation was termed "an embarrassment".

Sustainability in holistic terms is often contradictory to public perceptions and frequently results in propositions of what essentially is 'sustainability to a degree'. This, however, is another Trojan horse, as it appears to be an innocuous concession, when in fact it compromises the entire enterprise. Degrees of sustainability make no sense; sustainability is a state, not a process. It either is, or is not. Leaving even one subset of processes at work that undermines sustainability, and even if the process may be slow and a small part of the material flow (e.g. trace minerals), it is only a matter of time before that process takes the system its own way. The only successful strategy will be based on hierarchical ecosystem considerations, which are independent of public concerns and should be linked with the proper hierarchical level of decision making (Monjeau 2010). It took a thousand years for Sumerian civilization to disappear two millennia before Christ. Their agro-ecosystem was almost sustainable. The gradual process of salinization through Sumerian irrigation resulted in the collapse of their society. "Almost sustainable" means "not sustainable" in the long term. The depletion of natural resources, particularly soil fertility, has resulted repeatedly in civilizations disappearing (Diamond 2005).

As proposed by Fernandez et al., there should be audits to unmask cases of false conservation claims. This includes protected areas, but also NGOs and fraudulent politicians. In this way the global funds destined to conservation objectives could be concentrated in those cases where fulfillment is guaranteed. Obviously, acting in such a quixotic way, numerous false friends would become unmasked, converting themselves into enemies who no longer would invite us to their elegant cocktails. Will more courageous colleagues like Fernandez et al. remain in the lines of conservation? The hour has come to raise our hands.

\section{References}

DeAngelis DL, 1992. Dynamics of Nutrient Cycling and Food Webs. London: Chapman \& Hall. http://dx.doi. org/10.1007/978-94-011-2342-6

Diamond JM, 2005. Collapse: How Societies Choose to Fail or Succeed. New York: Penguin Books.

Dyck WJ \& Cole DW, 1994. Strategies for determining consequences of harvesting and associated practices on long-term productivity. In: Dyck WJ, Cole DW \& Comerford 
NB (eds.). Impacts of forest harvesting on long-term site productivity. London: Chapman \& Hall. p. 13-40. http:// dx.doi.org/10.1007/978-94-011-1270-3_2

Flueck WT, 2009. Evolution of forest systems: the role of biogeochemical cycles in determining sustainable forestry practices. Ecology and Society, 14(2):r4. Available from: $<$ www.ecologyandsociety.org/vol14/iss2/>.

Flueck WT \& Smith-Flueck JM, 2006. Herbicides and forest biodiversity: an alternative perspective. Wildlife Society Bulletin, 34:1472-1478. http://dx.doi. org/10.2193/0091-7648(2006)34[1472:HAFBAA]2.0.CO;2

Flueck WT, Smith-Flueck JM \& Monjeau JA, 2011. Protected areas and extensive productions systems: a phosphorus challenge beyond human food. BioScience, 61(8):582. http:// dx.doi.org/10.1525/bio.2011.61.8.18
Flueck WT, et al. 2012. The implications of selenium deficiency for wild herbivore conservation: a review. European Journal of Wildlife Research, 58:761-780. http://dx.doi.org/10.1007/ s10344-012-0645-Z

Fernandez FAS, et al. 2012. How sustainable is the use of natural resources in Brazil? Natureza \& Conservação, 10:77-82. http://dx.doi.org/10.4322/natcon.2012.013

Monjeau JA, 2010. Conservation crossroads and the role of hierarchy in the decision-making process. Natureza \& Conservação, 8:112-119. http://dx.doi.org/10.4322/ natcon.00802002

Peterson MN, Peterson MJ \& Peterson TR, 2005. Conservation and the myth of consensus. Conservation Biology, 19:762-767. http://dx.doi.org/10.1111/j.1523-1739.2005.00518.x

Redford KH, 1992. The empty forest. BioScience, 42:412-422. http://dx.doi.org/10.2307/1311860

Received: December 2012

First decision: January 2013

Accepted: February 2013 